Original article

\title{
Childhood physical maltreatment with physical injuries is associated with higher adult psychopathology symptoms
}

\author{
Diogo Lamela ${ }^{\mathrm{a}, *}$, Bárbara Figueiredo ${ }^{\mathrm{b}}$ \\ a Lusófona University of Porto, Rua Augusto Rosa, 24, 4000-098 Porto, Portugal \\ ${ }^{\mathrm{b}}$ University of Minho, R. da Universidade, 4710-057 Braga, Portugal
}

\section{A R T I C L E I N F O}

\section{Article history:}

Received 21 February 2017

Received in revised form 25 April 2018

Accepted 26 April 2018

Available online 29 May 2018

\section{Keywords:}

Physical maltreatment

Psychopathology

Distress

Injury

Child maltreatment

Child abuse

\begin{abstract}
A B S T R A C T
Background: Previous research has neglected the distinction between childhood physical maltreatment (CPM) behaviors and the physical sequelae resulting from CPM. Prior empirical work has combined CPM behaviors (e.g., beat, hit with a belt) and CPM physical sequelae (e.g., bruises, fractures) into a single conceptual category to predict adverse psychological consequences in adults. This is preventing the examination whether specific subgroups of CPM exposure may report a higher risk of psychopathology symptoms in adulthood. The aim of this study was to examine whether distinct experiences of CPM histories (no physical maltreatment, physical maltreatment only, and physical maltreatment with physical sequelae) would be differentially associated with specific psychopathology dimensions in adulthood. symptoms

Method: Data were drawn from the Portuguese National Representative Study of Psychosocial Context of Child Abuse and Neglect $(\mathrm{N}=941)$. Participants completed the Childhood History Questionnaire and the Brief Symptom Inventory.

Results: Three groups were created based on participants' experience of CPM assessed by the Childhood History Questionnaire. Participants who reported that suffered physical sequelae of the CPM exhibited significantly higher symptoms in all psychopathology dimensions than participants with no history of CPM and participants that were exposed to physical maltreatment without sequelae.

Conclusions: These findings suggest that clinicians should discriminate CPM behavior from CPM physical sequelae in order to increase effectiveness of mental health treatment with adults with history of CPM. Our findings are discussed in light of the evolutionary-developmental frameworks of adaptative development and cumulative risk hypothesis.
\end{abstract}

(c) 2018 Elsevier Masson SAS. All rights reserved.

\section{Introduction}

Child Physical Maltreatment (CPM) is a global public health issue, with $23 \%$ of the European adult population reporting having been physically maltreated in childhood [1]. CPM is defined as violence perpetrated by a household member (usually a parent or a primary caregiver) towards the child. CPM includes the child being beaten, kicked, burnt, hit with belts or other objects, or being threatened with knives or other weapons [2]. These violent behaviors substantially increase the risk of physical harm and the infliction of non-accidental physical injury to a child, including bruises, bites, bone fractures, cuts, welts, and burns [2]. The presence of physical injury resulting from a violent behavior toward the child is considered as an operational marker of the CPM

\footnotetext{
* Corresponding author.

E-mail address: lamela@ulp.pt (D. Lamela).
}

severity [3-5]. In accordance with the widely-adopted Modified Maltreatment Classification System, CMP severity is operationalized as a dimensional construct that describes different levels of the seriousness of a given act of maltreatment in function of the harmfulness of physical sequelae caused by the violent behavior $[4,6]$. CMP severity might range from dangerous behaviors but with no physical injuries or marks indicated (the lowest level of severity) to permanent disability, scarring, disfigurement, or fatality (the highest level of severity) [6].

Strong relationships between criteria of CPM classification (such as CPM type, frequency, chronicity) and psychopathology symptoms and/or psychiatric disorders in adults have been described in literature [7,8]. In particular, the frequency and chronicity of CPM exposure are being associated with an increased risk of earlier onset and higher severity of psychopathology symptoms, including depression, anxiety, alcohol dependence, psychotic symptoms, posttraumatic symptoms, and suicidal behaviors [9-11]. Despite these well-established findings, 
differential associations between distinct CPM patterns and the emergence of specific psychological problems in adulthood have remained surprisingly unexplored at an empirical level [8]. Little is known about whether specific subgroups of CPM exposure may report a higher risk of psychopathology symptoms in adulthood.

This limitation might be partially explained through methodological reasons. Previous research has neglected the potential clinical utility of discriminating CPM behaviors from the physical sequelae resulting from CPM. Prior empirical work has combined the presence and/or frequency of CPM behaviors (e.g., beat, hit with a belt) and CPM physical sequelae (e.g., bruises, fractures) into a single conceptual category to predict adverse psychological consequences in adults [12-14]. This methodological option is preventing the detection of differential associations between distinct CPM histories and psychopathology symptoms in adulthood. This is particularly critical since prior research in other types of child abuse suggest that the presence of abuse-related physical sequelae is associated with a heightened risk of adult psychiatric disorders $[15,16]$. In particular, some studies show that adults who were exposed to severe forms of sexual abuse (e.g., injuries related to sexual abuse) reported higher prevalence of mental health problems than non-exposed or low-severity exposed adults [1719]. These findings in sexual abuse suggest that a similar pattern of associations in CPM may emerge, in which a more detrimental association between the history of CPM with physical sequelae and later psychopathology symptoms might be expected.

To our knowledge, no previous research has tested this hypothesis directly. However, this assumption is conceptually supported. First, as physical sequelae are more likely to occur during more violent episodes of maltreatment, they are likely to be perceived as significant and real threats to survival. According to the evolutionary-developmental frameworks of adaptative development [20,21], children facing life-threatening environments develop and activate a pattern of physiological, behavioral, and emotional responses to monitorize and respond to an environment of imminent and inescapable threat. The continual activation of these responses is adaptive to competently survive in violent contexts, but it has longterm developmental costs, adversely affecting the development of the nervous, neuroendocrine, and immune systems [22]. More specifically, children exposed to highly-threatening environments develop overtime altered nervous and neuroendocrine functional activity characterized by high responsivity and basal activity in both the hypothalamic-pituitary-adrenal axis (HPA-axis) and the sympathetic nervous system(SNS), as well as by a low tone and responsivity of the parasympathetic nervous system (PNS) [21]. This pattern of stress reactivity functioning is thought to be the major mechanism linking highly adverse experiences (e.g., exposure to physical sequelae CPM) and risk of psychopathology [23].

The exposure to the physical sequelae of CPM might also induce children to interpret the parenting subsystem as an even more threating, unpredictable, and harmful environment [24]. The emotional security theory suggests that such a stressful nurturing environment undermines children's sense of emotional security and safety in parent-child relationships, impairing children's internal representations of the abusive parent as a reliable caregiver to fulfill their instrumental and emotional needs $[24,25]$. This may lead to a disturbance in attachment security and development of hypo and overreactive emotional and behavioral strategies to cope with such adverse parenting outcomes [20]. As a result, these emotional and behavioral difficulties exert a deleterious impact on individuals' abilities to successfully negotiate subsequent developmental tasks, increasing the risk of later psychopathology symptoms [26].

To provide additional insight into the associations between the history of CPM and psychopathology symptoms in adulthood, it is also crucial to consider that distinct associations may occur between CPM (with and without sequelae) and different psychopathology dimensions. Past research has mainly examined the association between CPM and depression and anxiety disorders [27]. In addition, previous studies tested primarily this association in clinical samples, using almost exclusively golden-standard measures to diagnose psychiatric disorders $[28,29]$. This categorical approach based on the notion of the presence or absence of psychopathology symptoms [30] precludes, however, the possibility of different histories of CPM exposure being associated with the co-occurrence of distinct types of clinical symptoms. Therefore, a dimensional approach to psychopathology allows a more finegrained analysis of the full-range presence of symptoms, regardless of whether the formal criteria of diagnosis have been met $[30,31]$. In particular, by assuming a continuum in psychopathology intensity, this approach provides additional insights into the comorbidity of symptoms, as well as whether and to what extent the psychopathology grouping of symptoms varies under distinct consequences of CPM.

In order to address these limitations, this study sought to examine differential associations between three types of histories of CPM and psychopathology symptoms in adulthood. Consistent with our rationale, we hypothesized that adults with no history of CPM would show the lowest levels of psychopathology when compared with adults exposed to CPM with or without physical sequelae. We also hypothesized that, among adults exposed to CPM, those who reported CPM-related physical sequelae would exhibit the highest levels of symptoms across all assessed psychopathological dimensions.

\section{Method}

\subsection{Participants and procedure}

This cross-sectional study is a secondary analysis of existing data of the Portuguese National Representative Study of Psychosocial Context of Child Abuse (PNRSAB). The total sample of the PNRSAB The primary research goals of the PNRSAB were to describe the prevalence of child physical maltreatment and to examine the associations between CPM and psychopathology symptoms.

The total sample comprised 941 adults (55\% women). Participants were mothers and fathers of children randomly selected in five public elementary schools in Northern Portugal (sample selection procedures are described in-depth to follow [32]). After being informed about the research aims and ethical procedures, adults who consented to participate completed and returned the assessment protocols and the letters of informed consent in sealed envelopes provided by the research team. This community schoolbased survey received ethical approval from the regional education authorities (Direcção Regional da Educação do Norte). A comparison to the national population statistics for marital status, education level, and income in the year that participants' data were collected revealed that the current sample is representative of the Northern Portuguese population [33].

The participants' mean age was 37.15 years $(S D=6.26$; range $=22$ -59 ). With respect to marital status, $91.3 \%$ of the sample were married or in cohabitation, and $8.7 \%$ were divorced, single, or widowed. Five hundred and ninety-seven (63.4\%) participants had until a 9th-grade compulsory education level, and 344 (36.6\%) participants had a high school or college degree. Most mothers (66.5\%) reported an income lower than the average national salary $(765 €)$.

\subsection{Measures}

CPM perpetrated by a parent or a primary caregiver during childhood and/or adolescence (0-18 years) was assessed with the 
Childhood History Questionnaire (CHQ)[34]. The CHQ is a retrospective self-report measure that assesses adults' exposure to physical abusive behaviors and CPM-related physical sequelae during childhood and adolescence. The main CHQ question is: "As a child, did you receive any of the following from one of your parents or another adult?" In a 5-point Likert-scale (from 0 to 4), respondents were asked to recall the presence and frequency (i.e., never, rarely, occasionally, often, and very often) of four physically abusive behaviors (whipping, slapping/kicking, poking/ punching, and hair-pulling). Respondents were then requested to indicate the presence of five potential physical sequelae resulting from those physical abusive behaviors (i.e., bruises/welts, cuts/ scratches, dislocations, burns, and bone fractures). Three scoring methods can be applied to analyze CHQ answers. The first method is the computation of a total score by summing respondents' answers to each of the nine items; the second method is the computation of two subtotal scores: a subtotal score for the frequency of the physically abusive behaviors (4 items), and a subtotal score for the frequency of CPM-related physical sequelae (5 items). The third method is a dichotomizing procedure by scoring the presence or absence of any exposure to physically abusive behaviors and presence or absence of any physical sequelae related to CPM exposure. As the adults' childhood history of CPM exposure was not a primary variable of interest of the PNRSAB, the CHQ were manually scored by the research team, and only the final scores were entered in the database. Data regarding to frequency of exposure to physically abusive behaviors were scored using the second method (computing a subtotal score), and the third method (dichotomizing procedure) was employed to score the presence/absence of any CPM-related physical sequelae. The Portuguese version of the CHQ showed good psychometric properties [32]. In the current sample, internal consistency was very good (Kuder-Richardson-20 $=.81$ ).

Psychopathology symptoms were measured with the Brief Symptom Inventory [35]. This widely-used 53-item self-report inventory assesses nine primary psychopathology symptom dimensions: depression, hostility, anxiety, phobic anxiety, obsessive-compulsive, psychoticism, paranoid ideation, somatization, and interpersonal sensitivity. Each item is rated on a 5-Likert point scale (from 0 'not at all' to 4 'extremely'). Additionally, the General Severity Index (GSI) was computed, since it is the single best global indicator of current psychopathology distress levels. Higher scores represent greater psychopathology symptoms. The Portuguese version of the BSI showed adequate psychometric properties [36]. Cronbach's alpha for the current sample ranged from 0.73 (psychoticism subscale) to 0.88 (depression subscale).

\subsection{Participants' assignment to the CMP groups}

The CHQ was used to assign participants to one of the three physical maltreatment groups, according to their experience of physical maltreatment until 18 years of age. The assignment was conducted using a two-step procedure, based on participants' answers regarding (1) the exposure to physically abusive behaviors and (2) the presence of physical sequelae resulted from the exposure to physically abusive behaviors. The groups' assignment procedure is displayed in Fig. 1.

In step 1, we analyzed the participants' reports about the exposure to the five $\mathrm{CHQ}$ listed physically abusive behaviors. Respondents who indicated never or rarely experiencing any of those physically abusive behaviors were assigned to the nonmaltreatment group (NM; $N=245,26 \%$ of the total sample). We decided to include participants with rare experiences of CPM in the non-maltreated group based on recent work that showed that single or rare events of physical abuse in childhood did not increase the risk of psychopathology symptoms in adulthood, either for women or men [37-39].

The remaining 696 participants reported they had been occasionally, often, or very often exposed to at least one of physically abusive behaviors. In step 2, we analyzed answers of these remaining 696 participants regarding the presence of physical sequelae (i.e., bruise/welt, cut/scratch, dislocation, burn, or bone fracture) resulted from physically abusive behaviors. Participants reporting that never suffered physical sequelae resulting from physically abusive behaviors were assigned to the maltreatment with no physical sequelae group (MNS; $N=573,61 \%$ of the total sample). In contrast, participants who reported that they had suffered at least one physical sequelae resulting from a

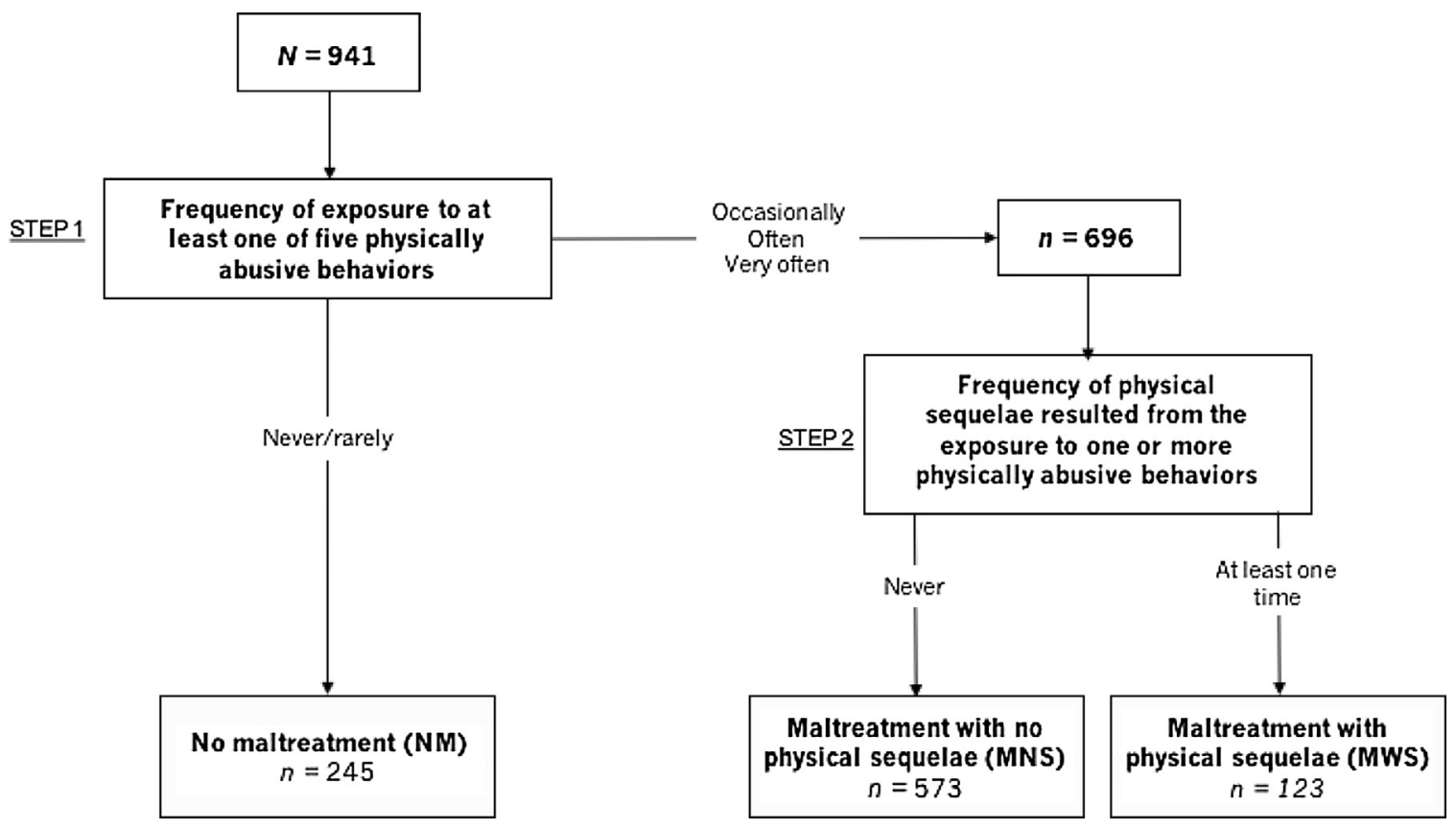

Fig. 1. Procedure for Participants' Assignment to the CPM Groups. 
physically abusive behavior perpetrated by a parent were assigned to the maltreatment with physical sequelae group (MWS; $N=123$, $13 \%$ of the total sample).

\subsection{Data analysis}

Analyses of variance (ANOVA) were used to examine group differences in age, and Kruskal-Wallis tests were conducted to assess group differences in gender, marital status, years of education, and family income/month distribution. Differences between the three groups in the psychopathology dimensions were first examined using ANOVA, followed by ANCOVA (analyses of covariance), adjusting for potential covariates. As multiple tests were conducted, Bonferroni-corrected post hoc tests were performed in order to prevent Type I Error.

\section{Results}

ANOVA and Independent Kruskal-Wallis tests were conducted to test differences between the groups in socio-demographic variables. Differences between groups were found in marital status, years of education, and family income/month (Table 1). Dunn's post hoc tests revealed that, when compared with the other groups, MWS group exhibited the lowest proportion of married/ cohabiting participants and also the lowest proportion of participants with more of 9 years of education and with a higher income than the average national salary. When compared with the NM group, MNS group exhibited the highest proportion of participants with more of 9 years of education and with a higher income than the average national salary. No differences between MNS and NM groups were found in the proportion of married/ cohabiting participants. No differences between groups were found in participants' age and gender (Table 1).
Next, ANOVA indicated significant group differences on all BSI dimensions, in which participants of the MWS group exhibited significantly higher scores than the other two groups. Table 1 displays mean unadjusted of BSI dimensions in the three maltreatment groups. ANCOVA was used to statistically control the potential effects of socio-demographic variables. Marital status, years of education, and family income/month were used as covariates since differences between groups were found on those variables. Table 1 shows adjusted means of BSI dimensions, with ANCOVA results revealing the same significant differences between groups. Neither the group means nor the significance levels were substantially changed after covariates adjustment. Participants of the MWS group obtained a GSI mean higher than the other two groups, while participants of the MNS group showed a GSI mean higher than participants of the NM group (Table 1).

\section{Discussion}

This study sought to test the associations between exposure to CPM with and without physical sequelae and psychopathology symptoms in a community sample of Portuguese adults. Our findings show that individuals within the MWS group reported the highest scores of symptoms in all assessed psychopathology dimensions. We also found that individuals within the NM group exhibited the lowest levels of psychopathology symptoms, with the exception in BSI anxiety-related subscales. Our findings are consistent with prior reports of an association between CPM and psychopathology symptoms in adulthood [9-11].

However, for the first time in literature, our study provides empirical evidence of the higher risk of psychopathology symptoms for the adults who reported the presence of physical sequelae related to CPM, including depressive, somatic, and psychotic symptoms. Taken together, the present findings offer

Table 1

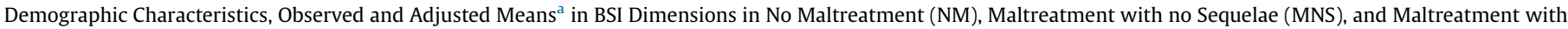
Sequelae (MWS), and Group Contrasts.

\begin{tabular}{|c|c|c|c|c|c|c|c|c|c|c|c|c|c|}
\hline & \multicolumn{6}{|l|}{ Group } & \multicolumn{7}{|c|}{ Kruskal-Wallis test } \\
\hline & \multicolumn{2}{|c|}{ NM $(N=245)$} & \multicolumn{2}{|c|}{ MNS (N = 573) } & \multicolumn{2}{|c|}{ MWS (N = 123) } & \multirow[b]{2}{*}{$\chi^{2}(2)$} & \multirow[b]{2}{*}{$\mathrm{p}$} & \multirow{2}{*}{\multicolumn{3}{|c|}{ Group contrasts $^{\mathrm{b}}$}} & & \\
\hline & $\mathrm{N}$ & $\%$ & $\mathrm{~N}$ & $\%$ & $\mathrm{~N}$ & $\%$ & & & & & & & \\
\hline Male & 103 & 42.0 & 268 & 46.8 & 52 & 42.3 & 1.96 & .375 & & n.s. & & & \\
\hline Married/cohabitation & 227 & 92.7 & 533 & 93.0 & 105 & 85.4 & 8.23 & .01 & NM & $1, \mathrm{MNS}>\mathrm{N}$ & AWS & & \\
\hline$>9$ years education & 85 & 34.7 & 265 & 46.2 & 27 & 22.0 & 28.87 & .001 & MNS & $\mathrm{S}>\mathrm{NM}>\mathrm{I}$ & MWS & & \\
\hline \multirow{2}{*}{$\begin{array}{l}\geq \text { Average national } \\
\text { salary }(765 €)\end{array}$} & 96 & 29.2 & 290 & 50.6 & 40 & 32.5 & 18.33 & .001 & MN & $S>N M>1$ & MWS & & \\
\hline & Mean & SD & Mean & SD & Mean & SD & $\begin{array}{l}\mathrm{F} \\
(2,940)\end{array}$ & $\mathrm{p}$ & $\begin{array}{l}\text { Adjusted } \\
\mathrm{NM} \\
\text { mean }^{\mathrm{a}}\end{array}$ & $\begin{array}{l}\text { Adjusted } \\
\text { MNS } \\
\text { mean }^{\mathrm{a}}\end{array}$ & $\begin{array}{l}\text { Adjusted } \\
\text { MWS } \\
\text { mean }^{\text {a }} \\
\end{array}$ & $\begin{array}{l}\text { Adjusted p } \\
\text { value }^{\mathrm{a}}\end{array}$ & Group contrasts $^{\mathrm{d}}$ \\
\hline Age (years) ${ }^{c}$ & 36.99 & 6.72 & 37.10 & 6.03 & 37.38 & 6.03 & .16 & .851 & & & & & n.s. \\
\hline \multicolumn{14}{|l|}{ BSI dimension } \\
\hline Depression & 2.28 & 3.05 & 3.13 & 3.57 & 4.62 & 4.96 & 16.66 & .001 & 2.26 & 3.20 & 4.37 & .001 & MWS $>$ MNS $>$ NM \\
\hline Hostility & 2.88 & 2.48 & 3.54 & 2.87 & 4.48 & 3.43 & 12.78 & .001 & 2.78 & 3.61 & 4.40 & .001 & $\mathrm{MWS}>\mathrm{MNS}>\mathrm{NM}$ \\
\hline Anxiety & 3.36 & 3.00 & 3.83 & 3.23 & 5.23 & 4.29 & 12.75 & .001 & 3.36 & 3.86 & 5.19 & .001 & MWS > MNS, NM \\
\hline Phobic anxiety & 1.38 & 2.13 & 1.38 & 2.10 & 2.33 & 2.87 & 9.48 & .001 & 1.36 & 1.42 & 2.24 & .001 & MWS > MNS, NM \\
\hline Obsessive-compulsive & 4.24 & 3.57 & 5.14 & 3.53 & 5.79 & 4.48 & 8.47 & .001 & 4.24 & 5.14 & 5.81 & .001 & MWS $>$ MNS $>$ NM \\
\hline Psychoticism & 1.55 & 2.19 & 1.98 & 2.45 & 3.00 & 3.19 & 13.65 & .001 & 1.54 & 2.01 & 2.90 & .001 & $\mathrm{MWS}>\mathrm{MNS}>\mathrm{NM}$ \\
\hline Paranoid ideation & 3.75 & 3.27 & 4.59 & 3.58 & 5.98 & 3.89 & 16.04 & .001 & 3.67 & 4.68 & 5.72 & .001 & MWS $>$ MNS $>$ NM \\
\hline Somatization & 2.88 & 3.57 & 3.36 & 3.77 & 5.86 & 4.99 & 25.57 & .001 & 2.68 & 3.45 & 5.58 & .001 & MWS $>$ MNS $>$ NM \\
\hline $\begin{array}{l}\text { Interpersonal } \\
\text { sensitivity }\end{array}$ & 2.98 & 2.32 & 2.48 & 2.49 & 3.37 & 2.69 & 12.67 & .001 & 1.89 & 2.54 & 3.22 & .001 & MWS $>$ MNS $>$ NM \\
\hline $\begin{array}{l}\text { BSI General Severity } \\
\text { Index }\end{array}$ & 0.49 & 0.42 & 0.61 & 0.46 & 0.85 & 0.61 & 21.58 & .001 & 0.47 & 0.62 & 0.82 & .001 & MWS $>$ MNS $>$ NM \\
\hline
\end{tabular}

a Adjusted for marital status, education and income per month.

b Significant group differences on Kruskal-Wallis test at $p<.05$ using Dunn's post hoc test.

c Age ranges: NM group, 22-64 years; MNS group, 22-63 years; MWS group, 24-58 years.

d Significant group differences on ANOVA and ANCOVA at $p<.05$ using Bonferroni-corrected post hoc test. 
initial support for the clinical and conceptual utility of discriminating CPM behaviors from CPM physical sequelae in the assessment of CPM experiences and its association with later psychopathology symptoms. The current research reveals that psychopathology symptoms' scores were significantly distinct between the two groups of CPM, suggesting that physical sequelae may operate as a distinct risk factor in the mental health trajectories. Although hypothetical, we believe that these findings are consistent with emerging evolutionary-developmental perspectives of adaptive development which places the development of the stress response system within its proximal ecology when interpreting individual differences in mental health outcomes [23]. These frameworks assert that children calibrate their behavior in ways to increase their fitness within a specific environmental condition. In an environment of CPM episodes that cause physical injuries, children have to adapt their behavior to face immediate and unpredictable threats, including hypervigilance and extreme fight-flight responses. These behavioral adaptations in such hard conditions are mediated by the nervous and neuroendocrine systems, resulting in a specific physiological profile [23]. This vigilant profile (i.e., low to moderate PNS responsivity, and high SNS and HPA responsivity) is associated with elevated levels of aggressive/antisocial and depression/anxiety behaviors $[21,40]$. Despite its adaptative function to struggle with immediate threats in childhood, this physiological-behavioral pattern hampers individuals' efforts to cope successfully with later changes in their environments, leading to psychopathology symptoms in adulthood. Based on these frameworks, as CPM with physical injuries might be perceived as more threatening to survival, children exposed to such violent forms of CPM have to perform higher behavioral adaptations that are associated with extreme variations of this vigilant phenotype. Therefore, when compared with the other two groups, it makes sense that adults who report physical sequelae of CPM are those who report higher mental health problems. In partial support of this assertion, empirical research has associated the exposure to maltreatment with this particular physiological pattern and later psychopathology symptoms [41,42]. For example, a recent longitudinal study showed that maltreated youth were more likely than non-maltreated youth to present low cortisol levels, suggesting a high HPA responsivity [43]. However, none of these studies discriminated CPM behaviors from CPM physical sequelae.

By extension, our results also raise the possibility that the presence of physical sequelae in CPM episodes could operate as a stronger indicator of higher exposure to a risk constellation in childhood $[44,45]$. First, physical sequelae are more likely to be inflicted during more severe episodes of CPM [34]. Parents who perpetrate severe CPM are more likely to exhibit psychiatric disorders [46], higher anger dysregulation [47], and higher social risk [48], which are also documented as significant distal risk factors for the emergence of psychopathology symptoms in adulthood. In addition, CPM is highly likely to co-occur with other family risk factors [49] that cumulatively may constrain the developmental acquisition of internal and external adaptative coping resources that buffer the effects of exposure to stress [50]. Exposure to multiple sources of stress is thought to be a cumulative chain of risk that is longitudinally linked with the dysregulation of children's psychological, behavioral, and neurobiological self-regulatory processes that ultimately increases individuals' vulnerability to psychopathology in adulthood [5153]. Therefore, as CPM with physical sequelae is likely to co-occur with other family adversities it may also operate as a marker of exposure to cumulative risk during childhood that also increases the odds of psychopathology symptoms in adulthood [54]. Thus, differences in psychopathology dimensions across CPM groups may suggest that individuals exposed to CPM with physical sequelae may be exposed to a risk constellation beyond CPM. Further research is needed to address the role of the cumulative effect of stressors on the association between CPM and adult psychopathology symptoms.

Several limitations warrant discussion. First, the presence of physical sequelae resulting from CPM exposure assessed via CHQ was coded and entered in the PNRSAB database as a dichotomous variable (presence vs. absence of physical sequelae). This prior methodological option prevented the examination of the association between different levels of severity of physical sequelae and adults' psychopathology symptoms. The MWS group congregated all participants who reported physical sequelae regardless their severity and frequency. This dichotomization option precluded the inspection of the severity of CPM as a continuous dimension and also the examination of potential subtypes of severity in the MWS group. Despite our study was the first to provide empirical support for the association between CPM-related physical injuries and adults' psychopathology symptoms, future research should expand our results by controlling the CPM severity and also by exploring the differential association between different levels of physical sequelae and later mental health outcomes. Second, all constructs were only assessed using self-report measures. Despite that all measures used in the current research have demonstrated significant associations with interviewing and observational measures, multi-informant and multimethod procedures could have contributed to a higher accuracy of measurement and also decreased possible shared method variance. This is significantly more important in the assessment of CPM exposure since some previous research suggests moderate CPM retrospective selfreports and official records $[55,56]$. Second, temporal variations in the severity of psychopathology symptoms might be expected, as suggested by longitudinal studies [57]. However, due to the crosssectional design of the current study, the potential differential impact of these changes over time on our findings was not examined. Finally, the current research was only conducted mainly with young adults with children. While this relative homogeneity augments statistical confidence in the associations found, this limited variability restrains the generalization of these findings from adults without children or older adults.

\subsection{Clinical implications}

Our results may also have three major clinical implications. First, by showing differential associations between exposure to CPM with and without physical sequelae and adult psychopathology symptoms, mental health professionals should not only assess CPM behaviors but also routinely include measures of CPM physical sequelae in their assessment protocols. In addition, as CPM subgroups were associated with different psychopathology dimensions, our results may imply that clinical assessment can benefit from the inclusion of a dimensional approach of psychopathology, rather than a categorical approach of assessment of these constructs. A dimensional approach for the assessment of psychopathology may be required for the translation of our findings into more effective clinical interventions in primary care settings. Second, by identifying specific subgroups reporting a higher risk of specific problems in parenting and co-parenting, our findings may raise the necessity of selective preventive interventions. In primary care settings, clinicians should especially screen psychopathology symptoms in adults with history of exposure to CPM with physical sequelae. In particular, mental health professionals could identify individuals with high cognitive-affective depression symptoms and somatic complaints for early support and intervention. Finally, our results could be applied in the assessment of the early onset of psychopathology symptoms in children exposed to CPM. These findings highlight that early 
intervention and prevention initiatives should be designed for those children who report physical injuries related to CPM episodes because the presence of these injuries increases the risk of more detrimental mental health outcomes in adulthood.

\section{References}

[1] Sethi D., Bellis M, Hughes K, Gilbert R, Mitis F, Galea G. European report on preventing child maltreatment. Copenhagen: WHO Regional Office for Europe; 2013.

[2] Bifulco A, Brown GW, Harris TO. Childhood experience of care and abuse (CECA): a retrospective interview measure. J Child Psychol Psychiatry 1994;35:1419-35.

[3] Litrownik AJ, Lau A, Briggs E, Newton RR, Romney S, Dubowitz H. Measuring the severity of child maltreatment. Child Abuse Negl 2005;29:553-73.

[4] Manly JT, Cicchetti D, Barnett D. The impact of subtype, frequency, chronicity, and severity of child maltreatment on social competence and behavior problems. Dev Psychopathol 1994;6:121-43.

[5] Griffin ML, Amodeo M. Predicting long-term outcomes for women physically abused in childhood: contribution of abuse severity versus family environment. Child Abuse Negl 2010;34:724-33.

[6] English D, Investigators L. Modified maltreatment classification system (MMCS). 1997.

[7] Gilbert AL, Bauer NS, Carroll AE, Downs SM. Child exposure to parental violence and psychological distress associated with delayed milestones. Pediatrics 2013;132.

[8] Norman RE, Byambaa M, De R, Butchart A, Scott J, Vos T. The long-term health consequences of child physical abuse, emotional abuse, and neglect: a systematic review and meta-analysis. PLoS Med 2012;9:e1001349.

[9] Cecil CAM, Viding E, Fearon P, Glaser D, McCrory EJ. Disentangling the mental health impact of childhood abuse and neglect. Child Abuse Negl 2017;63:106-19.

[10] Lowe SR, Meyers JL, Galea S, Aiello AE, Uddin M, Wildman DE, et al. RORA and posttraumatic stress trajectories: main effects and interactions with childhood physical abuse history. Brain Behav 2015;5:e00323.

[11] Hayashi Y, Okamoto Y, Takagaki K, Okada G, Toki S, Inoue T, et al. Direct and indirect influences of childhood abuse on depression symptoms in patients with major depressive disorder. BMC Psychiatry 2015;15:244.

[12] Agnew-Blais J, Danese A. Childhood maltreatment and unfavourable clinical outcomes in bipolar disorder: a systematic review and meta-analysis. Lancet Psychiatry 2016;3:342-9.

[13] Jaffee SR. Child maltreatment and risk for psychopathology in childhood and adulthood. Annu Rev Clin Psychol 2017;13:525-51.

[14] Lindert J, von Ehrenstein OS, Grashow R, Gal G, Braehler E, Weisskopf MG. Sexual and physical abuse in childhood is associated with depression and anxiety over the life course: systematic review and meta-analysis. Int J Public Health 2014;59:359-72.

[15] O'Leary P, Coohey C, Easton SD. The effect of severe child sexual abuse and disclosure on mental health during adulthood. J Child Sex Abuse 2010;19:275-89.

[16] Bernet CZ, Stein MB. Relationship of childhood maltreatment to the onset and course of major depression in adulthood. Depress Anxiety 1999;9:169-74.

[17] Sciolla A, Glover DA, Loeb TB, Zhang M, Myers HF, Wyatt GE. Childhood sexual abuse severity and disclosure as predictors of depression among adult AfricanAmerican and Latina women. J Nerv Ment Dis 2011;199:471-7.

[18] Glover DA, Burns T, Vargas J, Sciolla A, Zhang M, Glover DA, et al. Childhood sexual abuse severity and disclosure predict posttraumatic stress symptoms and biomarkers in ethnic minority women and disclosure predict posttraumatic stress symptoms and biomarkers in ethnic. J Trauma Dissociation 2010;11:152-73.

[19] Cutajar MC, Mullen PE, Ogloff JRP, Thomas SD, Wells DL, Spataro J. Psychopathology in a large cohort of sexually abused children followed up to 43 years. Child Abus Negl 2010;34:813-22.

[20] Ellis BJ, Boyce WT, Belsky J, Bakermans-Kranenburg MJ, van Ijzendoorn MH. Differential susceptibility to the environment: an evolutionaryneurodevelopmental theory. Dev Psychopathol 2011;23:7-28.

[21] Del Giudice M, Ellis BJ, Shirtcliff E. The adaptive calibration model of stress responsivity. Neurosci Biobehav Rev 2011;35:1562-92.

[22] Danese A, McEwen BS. Adverse childhood experiences, allostasis, allostatic load, and age-related disease. Physiol Behav 2012;106:29-39.

[23] Del Giudice M, Ellis BJ. Evolutionary foundations of developmental psychopathology. Dev. psychopathol. Vol. 1 theory method. 3rd ed. Hoboken, NJ: Wiley; 2016. p. 1-58.

[24] Davies P, Martin M. Children's coping and adjustment in high-conflict homes: the reformulation of emotional security theory. Child Dev Perspect 2014;8:242-9.

[25] Davies PT, Forman EM, Rasi JA, Stevens KI. Assessing children's emotional security in the interparental relationship: the security in the interparental subsystem scales. Child Dev 2002;73:544-62.

[26] Coe JL, Davies PT, Sturge-Apple ML. The multivariate roles of family instability and interparental conflict in predicting children's representations of insecurity in the family system and early school adjustment problems. J Abnorm Child Psychol 2017;45:211-24.
[27] Norman RE, Byambaa M, De R, Butchart A, Scott J, Vos T. The long-term health consequences of child physical abuse, emotional abuse, and neglect: a systematic review and meta-analysis. PLoS Med 2012;9:e1001349.

[28] Scott KM, McLaughlin KA, Smith DAR, Ellis PM. Childhood maltreatment and DSM-IV adult mental disorders: comparison of prospective and retrospective findings. Br J Psychiatry 2012;200:469-75.

[29] Green JG, McLaughlin KA, Berglund PA, Gruber MJ, Sampson NA, Zaslavsky AM, et al. Childhood adversities and adult psychiatric disorders in the national comorbidity survey replication I. Arch Gen Psychiatry 2010;67:113.

[30] Widiger TA, Gore WL, Widiger TA, Gore WL. Dimensional versus categorical models of psychopathology. Encycl. Clin. Psychol.. Hoboken, NJ, USA: John Wiley \& Sons, Inc.; 2015. p. 1-12.

[31] Hudziak JJ, Achenbach TM, Althoff RR, Pine DS. A dimensional approach to developmental psychopathology. Int J Methods Psychiatr Res 2007;16:S16-23.

[32] Figueiredo B, Bifulco A, Paiva C, Maia Â, Fernandes E, Matos R. History of childhood abuse in Portuguese parents. Child Abuse Negl 2004;28:669-82.

[33] Lamela D, Figueiredo B. Parents' marital status and child physical abuse potential: the mediation of depression symptoms. J Child Fam Stud 2016;26:1068-76.

[34] Milner JS, Robertson KR, Rogers DL. Childhood history of abuse and adult child abuse potential. J Fam Violence 1990;5:15-34.

[35] Derogatis LR, Melisaratos N. The brief symptom inventory: an introductory report. Psychol Med 1983;13:595-605.

[36] Canavarro C. Inventário de sintomas psicopatológicos: BSI [the brief symptoms inventory: BSI]. In: Simões M, Gonçalves M, Almeida L, editors. Testes e provas psicológicas em port [psychological tests port]. Braga, Portugal: APPORT; 1999. p. 95-109.

[37] Rehan W, Antfolk J, Johansson A, Santtila P. Do single experiences of childhood abuse increase psychopathology symptoms in adulthood? J Interpers Violence 2016088626051664700.

[38] Davis JL, Petretic-Jackson PA, Ting L. Intimacy dysfunction and trauma symptomatology: long-term correlates of different types of child abuse. J Trauma Stress 2001;14:63-79.

[39] Greenfield EA, Marks NF. Identifying experiences of physical and psychological violence in childhood that jeopardize mental health in adulthood. Child Abuse Negl 2010;34:161-71, doi:http://dx.doi.org/10.1016/j.chiabu.2009.08.012.

[40] Ellis BJ, Del Giudice M. Beyond allostatic load: rethinking the role of stress in regulating human development. Dev Psychopathol 2014;26:1-20.

[41] Quevedo K, Doty J, Roos L, Anker JJ. The cortisol awakening response and anterior cingulate cortex function in maltreated depressed versus nonmaltreated depressed youth. Psychoneuroendocrinology 2017;86:87-95.

[42] Doom JR, Cicchetti D, Rogosch FA. Longitudinal patterns of cortisol regulation differ in maltreated and nonmaltreated children. J Am Acad Child Adolesc Psychiatry 2014;53:1206-15.

[43] Peckins MK, Susman EJ, Negriff S, Noll J, Trickett PK. Cortisol profiles: a test for adaptive calibration of the stress response system in maltreated and nonmaltreated youth. Dev Psychopathol 2015;27:1461-70.

[44] Repetti RL, Taylor SE, Seeman TE. Risky families: family social environments and the mental and physical health of offspring. Psychol Bull 2002;128:330-66.

[45] Lamela D, Figueiredo B. A cumulative risk model of child physical maltreatment potential: findings from a community-based study. J Interpers Violence 2018;33:1287-305.

[46] Walsh C, MacMillan H, Jamieson E. The relationship between parental psychiatric disorder and child physical and sexual abuse: findings from the Ontario health supplement. Child Abus Negl 2002;26:11-22.

[47] Rodriguez CM, Richardson MJ. Stress and anger as contextual factors and preexisting cognitive schemas: predicting parental child maltreatment risk. Child Maltreat 2007;12:325-37.

[48] Cancian M, Yang M-Y, Slack KS. The effect of additional child support income on the risk of child maltreatment. Soc Serv Rev 2013;87:417-37.

[49] Turner HA, Finkelhor D, Ormrod R, Hamby S, Leeb RT, Mercy JA, et al. Family context, victimization, and child trauma symptoms: variations in safe, stable, and nurturing relationships during early and middle childhood. Am J Orthopsychiatry 2012;82:209-19.

[50] Jaffee SR, Caspi A, Moffitt TE, Polo-Tomás M, Taylor A. Individual, family, and neighborhood factors distinguish resilient from non-resilient maltreated children: a cumulative stressors model. Child Abus Negl 2007:31:231-53.

[51] Kessler RC, McLaughlin KA, Green JG, Gruber MJ, Sampson NA, Zaslavsky AM et al. Childhood adversities and adult psychopathology in the WHO world mental health surveys. Br J Psychiatry 2010;197:378-85.

[52] Plant DT, Barker ED, Waters CS, Pawlby S, Pariante CM. Intergenerational transmission of maltreatment and psychopathology: the role of antenatal depression. Psychol Med 2013;43:519-28.

[53] Evans GW, Cassells RC. Childhood poverty, cumulative risk exposure, and mental health in emerging adults. Clin Psychol Sci 2014;2:287-96.

[54] Evans GW, Li D, Whipple SS. Cumulative risk and child development. Psychol Bull 2013;139:1342-96

[55] Newbury JB, Arseneault L, Moffitt TE, Caspi A, Danese A, Baldwin JR, et al. Measuring childhood maltreatment to predict early-adult psychopathology: comparison of prospective informant-reports and retrospective self-reports. Psychiatr Res 2018:96:57-64.

[56] Pinto RJ, Maia ÂC. A comparison study between official records and selfreports of childhood adversity. Child Abus Rev 2013;22:354-66.

[57] Mezuk B, Kendler KS. Examining variation in depressive symptoms over the life course: a latent class analysis. Psychol Med 2012;42:2037-46. 